Ciencia, Ambiente y Clima, Vol. 2, No. 2, julio-diciembre, 2019 •ISSN (impreso): 2636-2317• ISSN (en línea): 2636-2333

DOI: https://doi.org/10.22206/cac.2019.v2i2.pp43-52

\title{
EVALUACIÓN DE LA ACIDEZ EN VINAGRES COMERCIALIZADOS EN LA REPÚBLICA DOMINICANA
}

\section{Acidity evaluation in vinegars commercialized in the Dominican Republic}

\author{
Scarlet Dotel \\ Instituto Tecnológico de Santo Domingo (INTEC), Área \\ de Ciencias Básicas y Ambientales. Santo Domingo, \\ República Dominicana \\ Correo-e: scarletdotel202128@gmail.com \\ Penélope Pozo \\ Instituto Tecnológico de Santo Domingo (INTEC), Área \\ de Ciencias Básicas y Ambientales. Santo Domingo, \\ República Dominicana \\ Correo-e: penelopepozob@gmail.com
}

\author{
Carlos José Boluda \\ Instituto Tecnológico de Santo Domingo (INTEC), Área \\ de Ciencias Básicas y Ambientales. Santo Domingo, \\ República Dominicana \\ Correo-e: carlos.boluda@intec.edu.do \\ Yaset Rodríguez-Rodríguez \\ Instituto Tecnológico de Santo Domingo (INTEC), Área \\ de Ciencias Básicas y Ambientales. Santo Domingo, \\ República Dominicana \\ Correo-e: yaset.rodriguez@intec.edu.do
}

Recibido: 11/11/2019 • Aprobado: 21/11/2019

Cómo citar: Dotel, S., Pozo, P., Boluda, C. J., \& Rodríguez-Rodríguez, Y. (2019). Evaluación de la acidez en vinagres comercializados en la República Dominicana. Ciencia, Ambiente Y Clima, 2(2), 43-52. Doi: https://doi.org/10.22206/cac.2019.v2i2.pp43-52

\section{Resumen}

La evaluación de la calidad es un aspecto de máxima importancia para la industria alimentaria a nivel mundial. El vinagre es un producto alimenticio de consumo habitual y al igual que otros, precisa de análisis de sus propiedades fisicoquímicas para garantizar el cumplimiento de los estándares de calidad recogidas en las normativas nacionales (NORDOM 22 y 37, 2017). En esta investigación se evaluó la acidez de ocho muestras diferentes de vinagres comercializados en la ciudad de Santo Domingo, República Dominicana. Para ello, se utilizó una valoración potenciométrica con una disolución de hidróxido de sodio como agente valorante. Solo una de las muestras analizadas, con acidez de 4,87\% (v/v), cumplió con el valor establecido (5-6) \% por estas normas y con la información mostrada en su etiqueta. Cuatro de las siete muestras restantes presentaron valores superiores, por lo que su consumo pudiera ser perjudicial. En cambio, para dos de ellas, se obtuvieron

\begin{abstract}
Quality assessment is an aspect of vital importance for the global food industry. Vinegar is a product of habitual consumption and, like other food products; it requires an analysis of its physicochemical properties for compliance with the quality controls included in the national regulations (NORDOM 22 y 37, 2017). This research evaluates the acidity of eight samples of different kinds, marketed in the city of Santo Domingo, Dominican Republic. For this, a potentiometric titration is used with a sodium hydroxide solution as a titrating agent. Only one of the analyzed samples, with acidity of $4,87 \%(\mathrm{v} / \mathrm{v})$, complied with the value established for this parameter (5-6) \%, by Dominican standards and with the corresponding value in the tag. Four of the seven samples have higher values, so their consumption could be harmful. On the other hand, two of them have values of 2,23\% and 3,88\% (v/v), much lower than these standards. It is necessary to expand
\end{abstract}


valores de acidez de 2,23 \% y 3,88 \% (v/v), muy inferiores a los fijados por ambas normas. Si bien es necesario ampliar esta investigación para confirmar los resultados obtenidos, estos sugieren que los vinagres comercializados en el país pudieran incumplir con los valores de acidez indicados por las normativas vigentes.

Palabras clave: vinagre; ácido acético; porcentaje de acidez; calidad; inocuidad.

\section{Introducción}

La industria alimentaria dedica importantes recursos para la evaluación de la calidad de sus productos, con el objeto de asegurar su inocuidad (Guerrero, 2009). Producir alimentos aptos para el consumo humano (Morón, 2001) es una necesidad impuesta por la sociedad y por las normativas en seguridad alimentaria. Por su parte, los consumidores demandan productos de calidad, con garantías para su salud, aspecto que se valida cuando la información presentada en sus etiquetas es veraz. Además, deben denunciar las deficiencias, fraudes e incumplimientos de la normativa ISO 22000 (Gallego, 2012).

El vinagre, del latín "vinum acre", "vino agrio", es un líquido de carácter agrio y astringente, producido mediante fermentación ácida del vino, y compuesto principalmente de ácido acético y agua (Real Academia Española, 2018). Contiene además varios ácidos orgánicos como: láctico, málico y cítrico, por lo que el control de la acidez es necesario para asegurar su calidad (Kotani, Miyaguchi, Harada \& Kusu, 2003; Montalvo, 2004). Se produce a través de un doble proceso de fermentación, alcohólica y acética (Food and Agriculture Organization \& Organización Mundial de la Salud, 2009) a partir de materias primas de origen agrícola que contienen almidones y/o azúcares. Este es un proceso bioquímico, llevado a cabo por diferentes microorganismos, en el que se pueden diferenciar tres etapas (figura 1): la glucolítica, que produce piruvato a partir de glucosa, la fermentación alcohólica que this research to confirm results obtained, although these suggest, that kinds of vinegar marketed in the country, could fail to comply with the acidity values collected by both regulations.

Keywords: Vinegar; acetic acid; acidity percentage; quality; safety.

convierte este último en etanol y la fermentación acética, donde el alcohol etílico se oxida a ácido acético. Las dos primeras son realizadas por Saccharomyces cerevisiae: la glucólisis, ruta central del catabolismo de la glucosa transforma este monosacárido en dos moléculas de piruvato, mediante diez reacciones catalizadas enzimáticamente. Posteriormente, en la fermentación alcohólica el piruvato es descarboxilado a acetaldehído por la piruvato descarboxilasa y luego, reducido a etanol por la alcohol deshidrogenasa. Esto último regenera el $\mathrm{NAD}^{+}$necesario para continuar con la glucólisis (Nelson, Cox \& Lehninger, 2013).

La producción ácido acético es llevada a cabo por bacterias de ácido acético, un grupo heterogéneo de microorganismos aerobios utilizados a nivel industrial en la producción de vinagre. Este grupo incluye a Alphaproteobacteria, Acetobacter y Gluconobacter. Cuando estas bacterias gram-negativas utilizan etanol como sustrato producen ácido acético (figura 1). Adicionalmente, las bacterias del ácido acético realizan la oxidación incompleta de otros alcoholes y azúcares, como es la oxidación de la glucosa a ácido glucónico y del sorbitol a sorbosa (Madigan, Martinko, Bender, Buckley \& Stahl, 2015). Además de los ácidos mencionados, el vinagre puede contener cantidades variables de otros componentes opcionales (hierbas, especias, sal), los cuales le confieren un aroma y sabor peculiar característico de cada tipo de vinagre y están regulados por la Comisión del Codex Alimentarius (Mas, Torija, García-Parrilla \& Troncoso, 2014). 


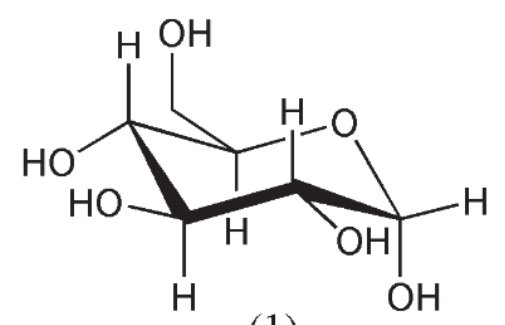

(1)

\section{Glucólisis}

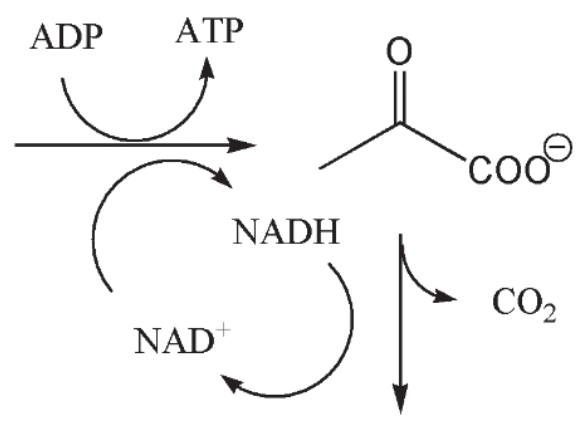

(3)

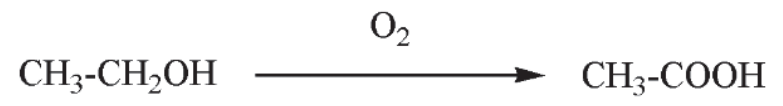

(2)

Fermentación alcohólica

(Saccharomyces cerevisiae)

\section{Fermentación acética}

(Bacterias del ácido acético)

Figura 1. Producción de ácido acético, ácido principal del vinagre.

Mediante glucólisis, la glucosa (1) es transformada en piruvato (2) que por acción secuencial de dos enzimas: piruvato descarboxilasa y alcohol deshidrogenasa rinde etanol. Este último es oxidado a ácido acético por las bacterias del ácido acético.

Fuente: elaboración propia.

El mercado global del vinagre ha presentado un crecimiento constante en las últimas décadas, debido a su popularidad entre los consumidores por su uso en saborizantes de alimentos y otras aplicaciones. Este hecho es validado por el informe de Expert Market Research, titulado "Global Vinegar Market Report and Forecast 2019-2024", en el cual se informa que el mercado global de este producto alcanzó los US\$ 1,28 mil millones en 2018 (Food \& Beverages, 2019). Además, en este se pronostica un crecimiento en el período de 2019-2024 en una CAGR (Tasa anual compuesta de crecimiento) del 1,8\%, para alcanzar US\$1,430 millones en 2024. Así, Europa en el 2019 se reconoce como el mayor mercado de comercialización de este producto, representando casi la mitad del mercado mundial (Food \& Beverages, 2019).

Este rubro es también soporte para República Dominicana, debido a sus diferentes usos en los hogares (Gómez, 2010). Diferentes empresas como: Baltimore
Dominicana (BALDOM), La Famosa, Constanza Agroindustrial y Victorina Agroindustrial (Caribe, 2015) lo producen a nivel nacional. Su producción, junto con la de bebidas alcohólicas, representaron el 33,1\% de las exportaciones totales de la República Dominicana a la región caribeña para el período 2014-2015, y fue uno de los productos más exportados de la región del Caribe y a países norteamericanos (Caribe, 2015). En el 2018 fueron exportados 6,8 millones de US\$ hacia Puerto Rico (Aduanas, 2018) y en el período de enero-junio de 2018 las exportaciones totales de bebidas alcohólica y de vinagre a Estados Unidos representaron el $3 \%$ (Cano, 2018).

$\mathrm{Al}$ igual que otros productos alimenticios, el vinagre debe cumplir con parámetros de calidad establecidos por normas nacionales e internacionales que rigen el sistema donde este se fabrica, distribuye y comercializa (Guerrero, 2009). Esto se realiza con el fin de garantizar la calidad durante su producción, 
comercialización e ingesta, además para determinar si el mismo ha sido adulterado durante su elaboración. Así su producción puede afectarse por la adición de ácido acético, para disminuir sus costos de elaboración (Pino, 2008).

Dentro de los parámetros de calidad que se determinan en este producto, la acidez total (expresada en función del ácido acético) es uno de los más importantes (Mas et al., 2014). Este no debe superar el intervalo entre 5-6\% (v/v) (BOE-A-1993-291227); (NORDOM 22 y 37, 2017). Valores superiores a estos pueden afectar de forma directa el organismo de los consumidores (Saínz, 2006).

La cuantificación de la acidez en vinagres puede realizarse por varias metodologías, las cuales abarcan desde los métodos clásicos de análisis hasta los instrumentales, donde se incluyen potenciométricos, cromatográficos, entre otros (Rudolph, 1960; Kotani et al., 2003; Sanarico, Motta, Bertolini \& Antonelli, 2003; Regmi, Palma, \& Barroso, 2012; McPherson, 2014). Desde el siglo Xvi los métodos volumétricos se han usado para cuantificar la acidez en muestras de vinagres (McPherson, 2014), en la actualidad, estos últimos se combinan con técnicas potenciométricas, para mejorar la calidad de los resultados (Nielsen, 2017; Checchetti \& Lanzo, 2015). De esta forma, se mejora la precisión del método a utilizar y en el caso de las valoraciones de vinagres coloreados se disminuyen los errores causados por la imprecisión al determinar los cambios de color en las volumetrías clásicas (Kotani et al., 2003).

Hoy en día, en la República Dominicana se comercializan varios tipos de vinagres que no reflejan en su etiquetado las especificaciones nutricionales, incluido el porcentaje de acidez, desconociéndose la calidad de estos productos. El objetivo principal de esta investigación es cuantificar este parámetro en estos vinagres y determinar si cumplen con el requisito de calidad establecido en las normas dominicanas (NORDOM 22 y 37, 2017).

\section{Materiales y métodos}

En esta investigación se colectaron ocho muestras provenientes de supermercados y colmados de la ciudad de Santo Domingo, República Dominicana. Estas se identificaron con las letras A, B, C, D, E, F, G y H, (ver tabla 1). Además, fueron colectadas tres réplicas por muestras en cada sitio de muestreo. La tabla 1 presenta algunos datos importantes de las mismas.

Tabla 1. Datos de las muestras de vinagres colectadas

\begin{tabular}{|c|c|c|c|c|c|}
\hline Muestra & $\begin{array}{c}\text { Lugar de } \\
\text { colecta }\end{array}$ & $\begin{array}{c}\text { Tipo de } \\
\text { envase }\end{array}$ & $\begin{array}{c}\text { Color } \\
\text { del } \\
\text { vinagre }\end{array}$ & $\begin{array}{c}\text { Tipo } \\
\text { de } \\
\text { vinagre }\end{array}$ & $\begin{array}{c}\text { Concentra- } \\
\text { ción } \\
\text { declarada } \\
\text { en la etiqueta } \\
\text { (\% v/v) }\end{array}$ \\
\hline A & Supermercado & Plástico* & Caramelo & $\begin{array}{c}\text { Vino } \\
\text { blanco }\end{array}$ & 5 \\
\hline B & Supermercado & Plástico* & Ámbar & Frutas & 6 \\
\hline C & Supermercado & Plástico* & Caramelo & F.E.P & 5 \\
\hline D & Supermercado & Plástico* & Caramelo & Frutas & 5 \\
\hline E & Supermercado & Plástico** & Caramelo & Manzana & 5 \\
\hline F & Supermercado & Plástico** & Caramelo & Frutas & 5 \\
\hline G & Colmado & Plástico & Ámbar & N.E & N.E \\
\hline
\end{tabular}

Nota: ${ }^{*}$ Tereftalato de polietileno No.2; ${ }^{* *}$ Tereftalato de polietileno No. 4; F.E.P fruta con esencia de pińa; N.E se refiere a No etiquetado

Fuente: elaboración propia.

La cuantificación del porcentaje de acidez de las muestras se realizó mediante valoración potenciométrica, utilizando una disolución de hidróxido de sodio $0,2 \mathrm{~mol} / \mathrm{L}$ como agente valorante. Esta fue estandarizada de forma previa con una disolución de ftalato ácido de potasio $0,1 \mathrm{~mol} / \mathrm{L}$, según se explica en el párrafo siguiente. Esta metodología es usada en la actualidad para evaluar la calidad de los vinagres 
por su sencillez, rapidez, costo, simplicidad y por la fiabilidad de los resultados obtenidos (Nielsen, 2017). Para la cuantificación de los puntos de equivalencia de cada muestra se procede a realizar un análisis de las gráficas por el método de la primera derivada. Estas se obtienen a partir de los datos para cada punto de las curvas de titulación ( $\mathrm{pH}$ versus volumen). Una vez construido el gráfico se identifica el punto de equivalencia de la titulación, con un cambio máximo para este punto (Checchetti \& Lanzo, 2015).

\section{Estandarización del hidróxido de sodio $(\mathrm{NaOH})$}

Se preparó $500 \mathrm{~mL}$ de disolución $\mathrm{NaOH}$ de concentración aproximada a partir de hidróxido de sodio (p.a) suministrado por la firma Merck. Esta se valoró potenciométricamente con una disolución de hidrógeno ftalato de potasio $0,1 \mathrm{~mol} / \mathrm{L}$, la cual fue preparada a partir de esta sal grado (p.a), suministrada por la firma Sigma-Aldrich. Para ello, 10 $\mathrm{mL}$ de la disolución anterior fueron introducidos en un matraz erlenmeyer de $125 \mathrm{~mL}$ con la ayuda de una pipeta y se ańadió $30 \mathrm{~mL}$ de agua destilada para incrementar el volumen con el objetivo de cubrir el electrodo de vidrio del $\mathrm{pH}$ metro marca Ohaus Starter 300. En la bureta de $50 \mathrm{~mL}$ se colocó la disolución de $\mathrm{NaOH}$ y se agitó con la ayuda de un agitador magnético marca Faithful SH-2, se añadieron volúmenes de $0,2 \mathrm{~mL}$ de la disolución de $\mathrm{NaOH}$ y se registraron los valores de $\mathrm{pH}$ en una plantilla Excel para graficar los valores de la primera derivada en función del $\mathrm{pH}$ versus volumen de valorante añadido (figura 2). El punto de la curva donde se observa la mayor inflexión corresponde al valor del volumen en el cual se alcanza el punto de equivalencia (Douglas et al., 2013). En este, la cantidad de sustancia en equivalente químico del valorante es igual a la del analito (Martínez, Castro, Lucena \& Zurita, 2015) y se procede a cuantificar la concentración exacta de la disolución de hidróxido de sodio en mol/L. Se realizó el cálculo para cada una de las tres réplicas y se determinó su valor medio (González, 2014).

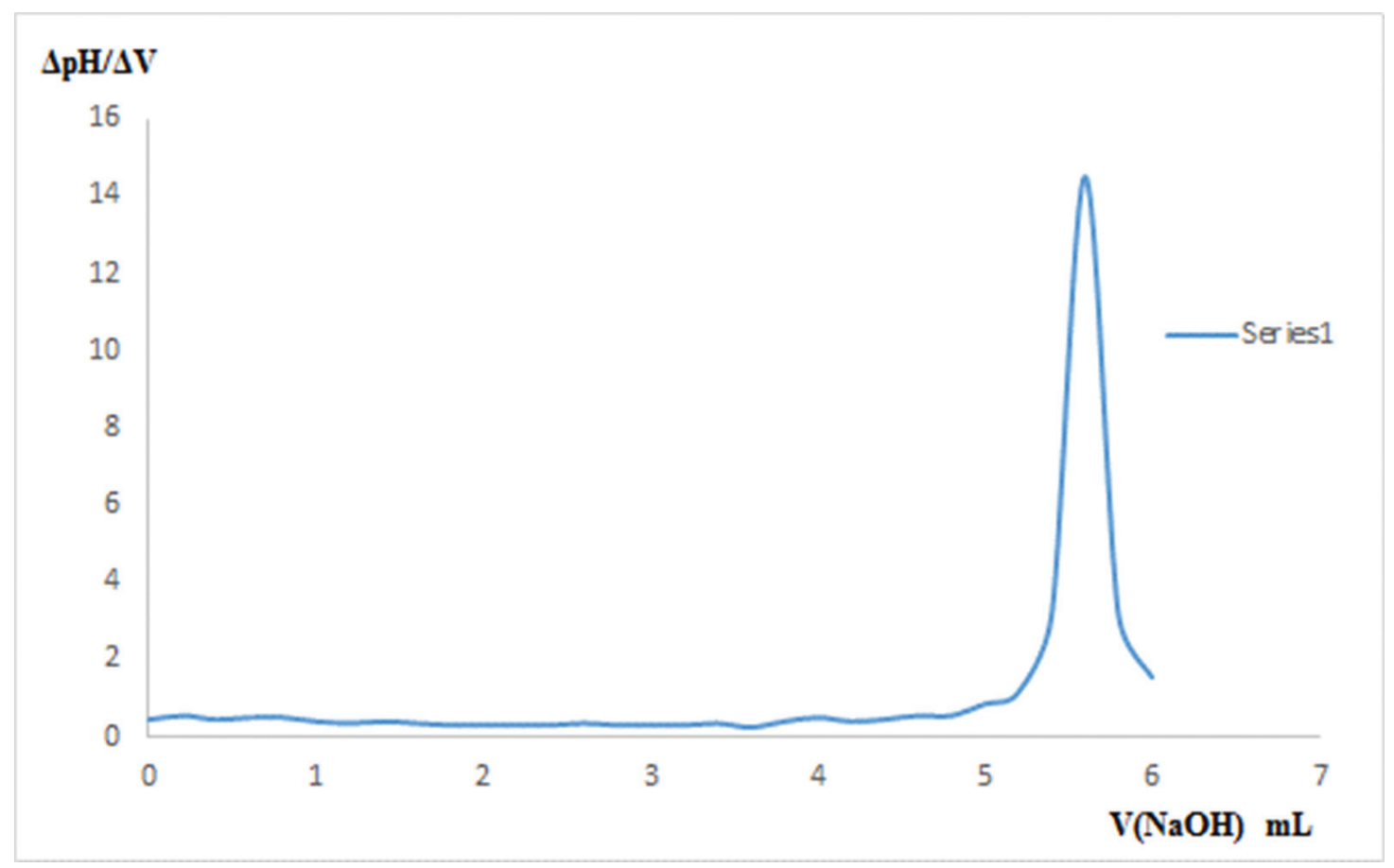

Figura 2. Curva de la primera derivada de la valoración potenciométrica correspondiente a la estandarización de $\mathrm{NaOH}$, con disolución de hidrógeno ftalato de potasio $0,1 \mathrm{~mol} / \mathrm{L}$.

Fuente: elaboración propia. 
Determinación potenciométrica del porcentaje de acidez en muestras de vinagres

Para la determinación del porcentaje de acidez en las muestras seleccionadas, de cada muestra de vinagre se tomó una alícuota de $5 \mathrm{~mL}$ y se enrasó con agua destilada en un matraz aforado de $100 \mathrm{~mL}$. De esta disolución, se tomó una alícuota $10 \mathrm{~mL}$ se trasvasó a un matraz erlenmeyer de $125 \mathrm{~mL}$, y se procedió de forma similar al epígrafe anterior para realizar la valoración correspondiente, con hidróxido de sodio $0,2 \mathrm{~mol} / \mathrm{L}$ como agente valorante. En este caso, la concentración de ácido acético en el vinagre se expresa en $(\% \mathrm{v} / \mathrm{v})$ y para ellos se realizó el cálculo a cada una de las tres réplicas y se determinó su valor medio.

\section{Análisis y discusión de los resultados}

La figura 3 muestra las curvas potenciométricas obtenidas en cada valoración, a partir de las cuales según el método de la primera derivada se obtuvieron los puntos de equivalencia para calcular las concentraciones de las muestras.

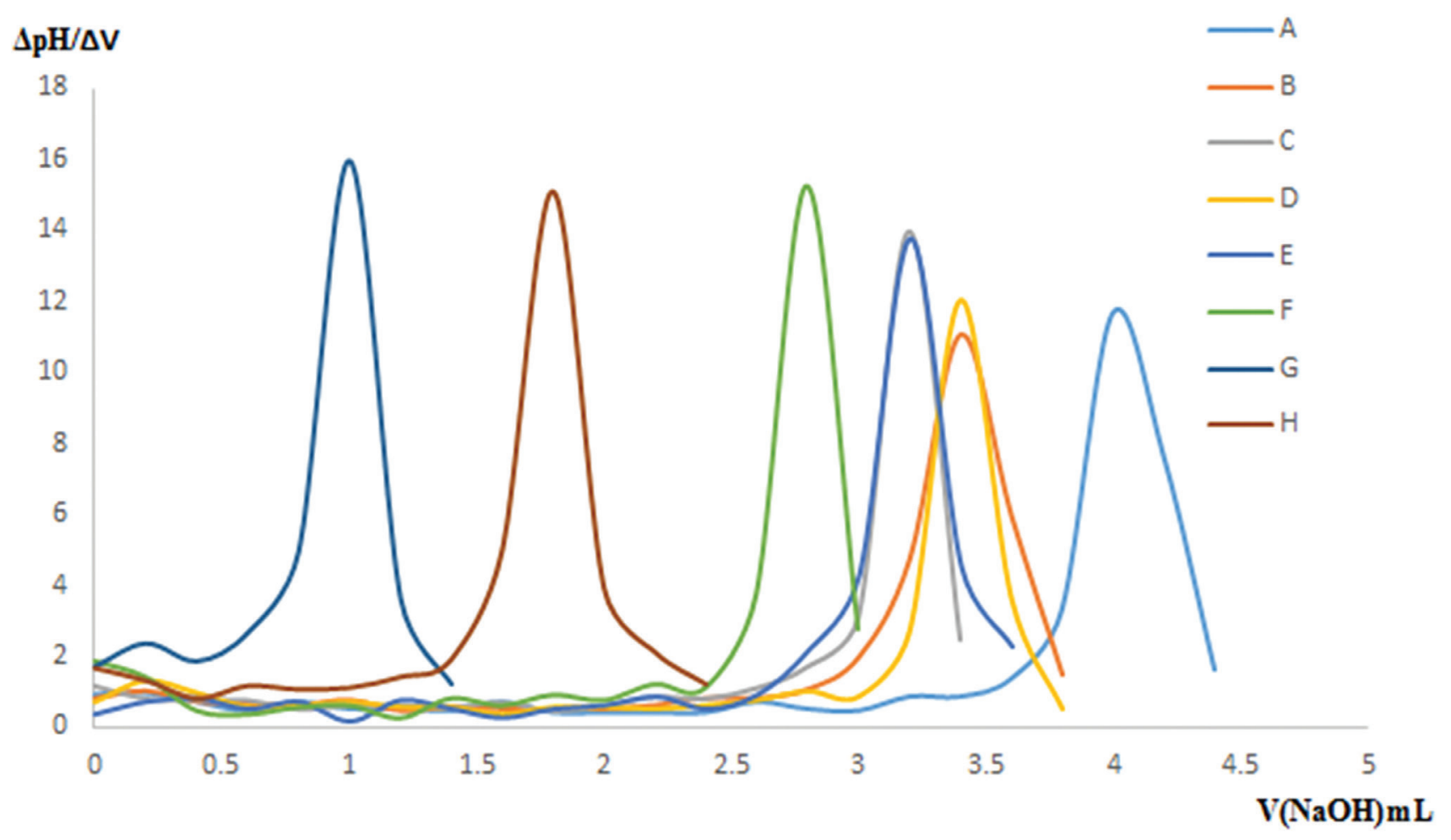

Figura 3. Curvas correspondientes a la primera derivada de las valoraciones potenciométricas para los vinagres evaluados.

Fuente: elaboración propia.

La tabla 2 muestra los valores de la concentración de ácido acético en las distintas muestras de vinagre, expresado como porcentaje (\%) (v/v) para las muestras estudiadas. Obsérvese cómo el coeficiente de variación determinado para cada muestra analizada no supera el $5 \%$, valor considerado umbral para evaluar la reproducibilidad de los resultados en métodos potenciométricos indicado por varios autores (Morris, Almarales, Romero \& Vidal, 2002; Hidalgo, Suárez \& Fernández, 2008). Esto indica que hay poca dispersión de los datos alrededor del valor promedio. 
Tabla 2: Resultados correspondientes a la concentración de ácido acético en muestras de vinagres comercializados en la República Dominicana, expresadas en $\%(\mathrm{v} / \mathrm{v})$

\begin{tabular}{|c|c|c|c|c|}
\hline Muestras & $\begin{array}{c}\text { Concen- } \\
\text { tración } \\
\text { media } \\
(\% \mathbf{v} / \mathbf{v})\end{array}$ & $\begin{array}{c}\text { Coefici- } \\
\text { ente de } \\
\text { ariación } \\
(\%)\end{array}$ & $\begin{array}{c}\text { Concen- } \\
\text { tración } \\
\text { experimental } \\
(\% \mathbf{v} / \mathbf{v})\end{array}$ & $\begin{array}{c}\text { Concentración } \\
\text { declarada en la } \\
\text { etiqueta } \\
(\% \mathbf{v} / \mathbf{v})\end{array}$ \\
\hline A & 4,84 & 0,12 & $4,84 \pm 0,086$ & 5 \\
B & 6,98 & 0,08 & $6,98 \pm 0,01$ & 6 \\
C & 6,50 & 2,34 & $6,50 \pm 0,60$ & 5 \\
D & 7,00 & 1,38 & $7,00 \pm 0,92$ & 5 \\
E & 6,70 & 1,22 & $6,70 \pm 1,18$ & 5 \\
F & 5,83 & 0,01 & $5,83 \pm 2,16$ & 5 \\
G & 2,23 & 3,90 & $2,23 \pm 0,49$ & N.E \\
H & 3,88 & 0,25 & $3,88 \pm 0,02$ & N.E \\
\hline
\end{tabular}

Nota: N.E se refiere a no etiquetado.

Fuente: elaboración propia.

El análisis de los datos recogidos en la tabla 2 revela que las muestras etiquetadas como B, C, D, E y F tienen valores de acidez que no coincide con los valores declarados para este parámetro en el etiquetado del producto. Esto constituye una violación de la normativa vigente por parte de los fabricantes de estos productos, por ser comercializados en concentraciones mayores a las especificadas en el etiquetado correspondiente (Instituto Nacional de Formación Técnica Profesional, 2019). Además, las muestras B, C, D y E tienen una concentración superior al intervalo (5-6) \%, lo que puede afectar la salud de las personas que lo consumen (Álvarez, 2013). En este sentido, pueden aparecer afecciones en el esófago, debido al aumento de los jugos gástricos propiciado por el incremento de ácido y puede causar reflujo en los consumidores (Bhattamisra et al., 2019). También el esmalte dental puede afectarse, por lo que en ocasiones pueden sentir que se destemplan los dientes, debilitándose y causando dańos a largo plazo (Fernández, 2011). Otro impacto negativo puede asociarse sobre los niveles de potasio en las personas que lo consumen (Food and Agriculture Organization, 2016). La muestra F se le cuantificó 5,83\% de acidez, estando en el intervalo declarado por las normas (5-6) \%. Sin embargo, al ser elaborado a base de frutas supera el límite permitido para este tipo de vinagre $5 \%$, de acuerdo con las normativas (NORDOM 22 y 37 , 2017). Es de señalar, que estos tipos de vinagres se comercializan en varios supermercados y colmados (tiendas suplidoras de alimentos) de la República Dominicana, por lo que puede existir un gran número de consumidores afectados, debido a que este producto es muy demandado por la población.

Por su parte, las muestras identificadas como $\mathrm{G}$ y H, corresponden a vinagres comercializados solo en colmados de la República Dominicana. Ambas presentan concentraciones de (2,23\% y 3,88\%) respectivamente, por debajo de los índices de calidad de los vinagres los cuales están (5-6) \% (NORDOM 22 y 37, 2017). Esto no indica necesariamente una violación de la normativa por parte de los productores, sino que podría deberse a una adulteración por dilución del producto original, antes de su envasado.

En el caso de la muestra G, el porcentaje obtenido es menor de la mitad del valor de acidez mínimo recogido por la normativa, por lo que se incumple claramente con este requisito. En la muestra $\mathrm{H}$, también está por debajo de este valor, pero es un poco más concentrada que la G. En estos dos casos, también resulta irregular la falta de etiquetado en el producto. Con relación a la muestra identificada con la letra $\mathrm{A}$, esta fue la única que presentó un valor de acidez, que cumple tanto con el valor presentado en la etiqueta, como con el establecido en la normativa vigente. 
Por medio de esta investigación, se comprobó que el control de la calidad de la producción de vinagres comercializados en el país no es satisfactorio. Los resultados obtenidos no son consecuentes con la información registrada en sus etiquetas y se incumplen con la normativa. Por otra parte, los productos comercializados no traen consigo un etiquetado que permita el conocimiento de datos nutricionales que son esenciales para el consumidor.

\section{Conclusiones}

Esta investigación permitió cuantificar el porcentaje de acidez de ocho muestras colectadas en supermercados y colmados de la ciudad de Santo Domingo, República Dominicana. La muestra identificada como A fue la única que presentó el porcentaje de acidez 4,84\% (v/v) consecuente con la información que se exhibe en su etiquetado $5 \%(\mathrm{v} / \mathrm{v})$.

Las muestras B, C, D y E tienen valores superiores al límite máximo $6 \%(\mathrm{v} / \mathrm{v})$ establecido en las normas dominicanas (NORDOM 22 y 37, 2017) y no son consecuentes con las informaciones que exhiben sus etiquetas.

El porcentaje de acidez de las muestras colectadas en los colmados e identificadas como G y H (2,23 y 3,88$) \%(\mathrm{v} / \mathrm{v})$ presentaron valores por debajo de los índices de acidez exigido por las normas dominicanas (NORDOM 22 y 37, 2017).

Si bien este es un estudio de carácter prospectivo, los resultados parecen reflejar que en República Dominicana el vinagre no se está comercializando con la calidad requerida. En algunos casos, este hecho podría incluso tener consecuencias negativas para la salud de los consumidores.

\section{Agradecimientos}

Los autores quieren agradecer a la MSc. Carmen María Hernández Toirac, al Dr. C. Luis Orlando Maroto Martín y a la Lic. Adriana Carolina Rojas de Guillén, por su ayuda para el desarrollo de esta investigación del Laboratorio de Servicios Analíticos y Ambientales, del Instituto Tecnológico de Santo Domingo (INTEC), donde se realizaron las actividades experimentales.

\section{Referencias}

Aduanas. (2018). Reporte de exportaciones. Recuperado de: https://siga.aduanas.gob.do/Descargas/ files/estadisticas/informes/comercio/ Revista-de-comercio-Enero-2018.pdf

Bhattamisra, S. K., Yan, V. L. Y., Lee, C. K., Kuean, C. H., Candasamy, M., Liew, Y. K., \& Sahu, P. S. (2019). Protective activity of geraniol against acetic acid and Helicobacter pylori-induced gastric ulcers in rats. Journal of Traditional and Complementary Medicine, 9(3), 206-214.

(BOE-A-1993-291227. (1997). Normas alimentarias del Congreso Nacional, (11). Disponible en; https://www.boe.es/diario_boe/txt.php? id=BOE-A-1997-19355. [Consultado 31 de agosto de 2019].

Cano, Á. (2018). El vinagre: propiedades y tipos. Recuperado de https://www.naturalcastello.com/vinagre-propiedades-tipos/

Caribe, S. (2015). El Contexto de Convergencia y Cooperación entre la República Dominicana y paises del Caribe. Recuperado de http://economia.gob.do/mepyd/wp-content/uploads/ archivos/uepesc/informe-pais/2015/ Convergencia.pdf. [Consultado 29 de septiembre 2019].

Checchetti, A., \& Lanzo, J. (2015). Qualitative Measurement of pH and Mathematical Methods for the Determination of the Equivalence Point in Volumetric Analysis. World Journal of Chemical. Education. 3(3), 64-69.

Douglas, A., Bhopal, R.S., Bhopal, R., Forbes, J.F., Gill, J.M.R., McKnight, J., Murray, G., Sattar, N., Sharma, A., Wallia, S., Wild, S., and Sheikh, A. (2013). Titulación potenciométrica. Recuperado de http://quimicaexperimental9. blogspot.com/2013/04/practica-20.html 
Food and Agriculture Organization \& Organización Mundial de la Salud. (2009). Normas alimentarias, 16. Disponible en http://www.fao.org/ tempref/codex/reports/alinorm 10/al33_ 13s.pdf

Food and Agriculture Organization. (2016). Calidad alimentaria. Disponible en http://www.fao. org/3/i9553es/i9553es.pdf. [Consultado 9 de septiembre de 2019].

Fernández, A. (2011). Calcio y Nutrición. Recuperado de https://www.sap.org.ar/docs/calcio.pdf. [Consultado 9 de septiembre de 2019].

Food \& Beverages. (2019). Italia continúa liderando el mercado mundial de vinagre en producción y exportaciones. Recuperado de https://www. bizvibe.com/blog/food-beverages/italy-leads-global-vinegar-market/. [Consultado 9 de septiembre de 2019].

Gallego Picó, A. (2012). Características de los alimentos y control de calidad. Aldaba, 36, 13-34.

Gómez, M. (2010). El vinagre: condimento de muchas recetas dominicanas. Recuperado de http:// www.revistasexcelencias.com/caribe/un-solo-caribe/cocinas-del-mundo/recetas-de-la-cocina-dominicana. [Consultado 9 de septiembre de 2019].

González, M. (2014). Preparación de una disolución de una base fuerte $(\mathrm{NaOH})$ y cálculo de su molaridad mediante volumetría ácido-base frente a hidrogenoftalato patrón. Práctica interactiva. Disponible en: https://rodin.uca.es/xmlui/ handle/10498/16750. [Consultado $25 \mathrm{de}$ octubre de 2019].

Guerrero, E. D (2009). Control de los procesos de elaboración, calidad y trazabilidad del Vinagre de Jerez, (tesis doctoral). Universidad Cádiz, España.

Hidalgo, C., Suárez, Y., \& Fernández, M. (2008). Validación de una técnica potenciométrica para determinar el grado de desacetilación de la quitosana. Ars Pharmacentica, 49(3), 245-257.
Instituto Nacional de Formación Técnico Profesional. (2019). Conservación de los alimentos. En Calidad de los alimentos, 04-06.

Kotani, A., Miyaguchi, Y., Harada, D., \& Kusu, F. (2003). A disposable voltammetric cell for determining the titratable acidity in vinegar. Analytical Sciences, 19(11), 1473-1476.

Madigan M.T., Martinko J.M., Bender K.S., Buckley D.H., Stahl D.A. (2015). Brock, Biología De Los Microorganismos, (14 ed.), Madrid, España: Pearson Education, 461-662.

Martínez Martínez, A., Castro Sánchez, M., Lucena Zurita, M., \&Zurita Ortega, F., (2015). Elección de titulación universitaria y expectativas de resultados delosadolescentes de Granada. Revista Española de Orientación y Psicopedagogía, 26 (3), 63-77. Asociación Española de Orientación y Psicopedagogía Madrid, España.

Mas, A., Torija, M. J., García-Parrilla, M. D. C., \& Troncoso, A. M. (2014). Acetic acid bacteria and the production and quality of wine vinegar. The Scientific World Journal, (2), 1-6.

McPherson, P. (2014). Practical Volumetric Analysis. ( $1^{\text {st }}$ ed.) Cambridge, UK: Royal Society of Chemistry.

Montalvo, M. C. M. (2004). La elaboración del vinagre en el s. XIx: discordia y enfrentamiento químico-biológico. En Historia de las ciencias y de las técnicas. Actas VIII Congreso de la Sociedad Española de Historia de las Ciencias $y$ de las Técnicas .687-702. Universidad de La Rioja.

Morón, C. (2001). Importancia del Codex Alimentarius en la seguridad y comercio alimentaria, Revista de Salud Pública y Nutrición, 2(3), 2-3.

Morris Quevedo, H. J., Almarales Arceo, A., Romero Viamonte, K., \& Vidal Colás, M. (2002). Validación de un método potenciométrico para la determinación de nitrógeno amínico en hidrolizados proteicos de microalgas. Revista Cubana de Farmacia, 36(1), 56-61. 
Nelson, D., Cox, M. \& Lehninger, A. (2013). Lehninger Principles of Biochemistry, (6 ed). New York, Estados Unidos: W.H. Freeman, p. 523, 524, 538, 540.

Nielsen, S. S. (2017). Food Analysis. (5 ${ }^{\text {th }}$ Ed.). New York, Estados Unidos: Springer International Publishing, 139-141.

NORDOM 22. (2017). Porcentaje de acidez en vinagres dominicanos. Disponible en: https:// www.indocal.gob.do/publicaciones/catalogo-de-normas/. [Consultado, 19 de septiembre de 2019].

NORDOM 37. (2017). Porcentaje de acidez en vinagres dominicanos. Disponible en: https:// www.indocal.gob.do/publicaciones/catalogo-de-normas/. [Consultado, 19 de septiembre de 2019].

Pino, M. A. (2008). Tratamientos Postfermentativos del Vinagre: Conservación en botella, envejecimiento acelerado y eliminación del plomo. Universitat Rovira i Virgili. Disponible en: https://www.tdx.cat/handle/10803/866,5. [Consultado 16 de octubre de 2019].
Real Academia Española (RAE). (2018). Disponible en: https://dle.rae.es/?id=bpuLj5x [Consultado el 25 de octubre de 2019].

Regmi, U., Palma, M., \& Barroso, C. G. (2012). Direct determination of organic acids in wine and wine-derived products by Fourier transform infrared (FT-IR) spectroscopy and chemometric techniques. Analytica Chimica Acta, 732, 137-144.

Rudolph, R. A. (1960). Identificación de aminoácidos en distintas variedades de vinagres por cromatografía sobre papel, (tesis doctoral). Facultad de Ciencias Exactas y Naturales. Universidad de Buenos Aires, Argentina.

Saínz, B. (2006). Alteración DelEquilibrio Ácido-Base. Disponible en: http://scielo.sld.cu/scielo.php?scrip$\mathrm{t}=$ sci_arttext\&pid=S0034-74932006000100011. [Consultado 19 de octubre de 2019].

Sanarico, D., Motta, S., Bertolini, L., \& Antonelli, A. (2003). HPLC determination of organic acids in traditional balsamic vinegar of Reggio Emilia. Journal of Liquid Chromatography or Related Technologies, 26(13), 2177-2187. 